\title{
Impact of Seminal Chemical Elements on the Oxidative Balance in Bovine Seminal Plasma and Spermatozoa
}

\author{
Eva Tvrdá, ${ }^{1}$ Norbert Lukáč, ${ }^{1}$ Monika Schneidgenová, ${ }^{1}$ Jana Lukáčová, ${ }^{1}$ Csaba Szabó, ${ }^{2}$ \\ Zofia Goc, ${ }^{3}$ Agnieszka Gren, ${ }^{3}$ and Peter Massányi ${ }^{1}$ \\ ${ }^{1}$ Department of Animal Physiology, Faculty of Biotechnology and Food Sciences, Slovak University of Agriculture, \\ Tr. A. Hlinku 2, 94976 Nitra, Slovakia \\ ${ }^{2}$ Department of Animal Physiology and Health, Szent István University, Páter Karoly utca 1, Gödöllö 2103, Hungary \\ ${ }^{3}$ Institute of Biology, Faculty of Geography and Biology, Pedagogical University of Krakow, ul. Podbrzezie 3, 31045 Kraków, Poland
}

Correspondence should be addressed to Eva Tvrdá; evina.tvrda@gmail.com

Received 28 April 2013; Revised 22 July 2013; Accepted 7 August 2013

Academic Editor: Daniel A. Feeney

Copyright (C) 2013 Eva Tvrdá et al. This is an open access article distributed under the Creative Commons Attribution License, which permits unrestricted use, distribution, and reproduction in any medium, provided the original work is properly cited.

\begin{abstract}
Mutual relationships between selected chemical elements ( $\mathrm{Na}, \mathrm{K}, \mathrm{Fe}, \mathrm{Cu}, \mathrm{Mg}$, and $\mathrm{Zn}$ ), basic motility characteristics (motility and progressive motility), and markers of the oxidative balance (superoxide dismutase, catalase, glutathione, albumin, and malondialdehyde) were investigated in bovine seminal plasma and spermatozoa. Computer assisted sperm analysis was used to assess the motility parameters; mineral concentrations were determined by the voltammetric method and flame absorption spectrophotometry; antioxidants and malondialdehyde were evaluated by UV/VIS spectrophotometry. Concentrations of chemical elements in both seminal fractions were in the following descending order: $\mathrm{Na}>\mathrm{K}>\mathrm{Zn}>\mathrm{Mg}>\mathrm{Fe}>\mathrm{Cu}$. Higher amounts of all minerals and nonenzymatic antioxidants were detected in the seminal plasma $(P<0.01 ; P<0.001)$, while higher MDA concentration and activity of enzymatic antioxidants were recorded in the cell lysates $(P<0.01 ; P<0.001) . \mathrm{Na}, \mathrm{Fe}, \mathrm{Cu}, \mathrm{Mg}$, and $\mathrm{Zn}$ were positively correlated with the motility and antioxidant parameters $(P<0.05 ; P<0.01 ; P<0.001)$. Inversely, $\mathrm{K}$ exhibited the positive associations with malondialdehyde $(P<0.05)$. This study demonstrates that most chemical elements are integral components of bovine semen and are needed for the protection against oxidative stress development.
\end{abstract}

\section{Introduction}

Various anthropogenic activities and natural environmental factors as well as other sources are of crucial importance for the reproductive potential of semen, both in animals and humans [1]. Chemical elements represent a vital ecophysiological component for the preservation and fertilization capacity of spermatozoa. Some of them are essential for proper sperm cell functions (e.g., sodium, Na; potassium, K; calcium, $\mathrm{Ca}$; magnesium, $\mathrm{Mg}$ ); others are required in relatively narrow limits (e.g., zinc, $\mathrm{Zn}$; copper, Cu; manganese, $\mathrm{Mn}$; cobalt, Co; selenium, Se; iron, Fe) [2, 3].

Mammalian seminal plasma and spermatozoa are known to contain a broad variety of macro- and microelements [1]. The influence of major biologically active inorganic components on spermatozoa viability parameters has been studied in animals as well as in humans [2-7]. Positive effects on the sperm cell motility, morphology, and concentration were reported particularly for $\mathrm{Zn}, \mathrm{Mg}$, Se, and $\mathrm{Ca}[4,5,7]$. $\mathrm{Fe}, \mathrm{Cu}$, and their compounds are essential metal cofactors for a variety of bioactive molecules; however, disturbances in their regulative absorption mechanism with subsequent aberrant concentrations may have a negative impact on the sperm viability and morphology $[2,3,8]$.

The role of chemical elements in natural antioxidant structures has recently attracted much scientific interest. Some minerals are required for cellular defense systems against free radicals (FR) [1]. It has been demonstrated that disturbances in their concentrations may lead to a reduction of antioxidant activities and subsequently increase the risk of oxidative stress (OS) development $[1,6]$. OS is a serious condition as FR, and their metabolites attack vital biomolecules including DNA, lipids, and proteins, altering enzymatic systems and cell signaling pathways and 
causing irreparable damage, apoptosis or necrosis [9]. The unique cellular architecture of spermatozoa, large quantities of polyunsaturated fatty acids, and low concentrations of FR scavengers render them to be particularly susceptible to OS. Meanwhile, the seminal plasma is an important protectant of spermatozoa against possible FR formation and distribution, as it contains an array of enzymatic as well as nonenzymatic antioxidants $[10,11]$.

A variety of data concerning the relationships between chemical elements, and antioxidant profile in semen have been currently published; however, the information is partial and related to whole semen or seminal plasma only. To our knowledge, no study is available on the relationships between seminal quality, chemical elements and markers of antioxidant status in both fragments of the ejaculate-the seminal plasma and spermatozoa fraction.

This study was therefore carried out to (1) evaluate selected chemical elements ( $\mathrm{Na}, \mathrm{K}, \mathrm{Cu}, \mathrm{Fe}, \mathrm{Zn}$, and $\mathrm{Mg}$ ) and markers of oxidative balance in bovine seminal plasma and spermatozoa and to (2) assess their mutual relationships as well as effects on the sperm motility characteristics. The examined motility and oxidative status parameters were as follows:

(i) motility (MOT): percentage of motile spermatozoa (motility $>5 \mu \mathrm{m} / \mathrm{s}$ ),

(ii) progressive motility (PROG): percentage of progressive motile spermatozoa (motility $>20 \mu \mathrm{m} / \mathrm{s}$ ),

(iii) superoxide dismutase (SOD): a major antioxidant enzyme that catalyses the conversion of two superoxides into oxygen and hydrogen peroxide $\left(\mathrm{H}_{2} \mathrm{O}_{2}\right)$,

(iv) catalase (CAT): an antioxidant enzyme which degrades $\mathrm{H}_{2} \mathrm{O}_{2}$ to water and oxygen, thereby completing the reaction started by $\mathrm{SOD}$,

(v) glutathione (GLH): the principal nonenzymatic antioxidant specialized in the prevention of oxidative damage to cellular components,

(vi) albumin (ALB): an important nonenzymatic protein with antioxidant properties,

(vii) malondialdehyde (MDA): a byproduct of lipid peroxidation (LPO) and a biomarker indicating the overall oxidative degradation of lipids.

\section{Materials and Methods}

2.1. Biological Material. Semen samples were collected in duplicates from 30 Simmental-Fleckvieh breeding bulls kept in the Breeding Centre of the Slovak Biological Services, Nitra, Slovakia, during late spring and early summer 2012. The animals were $4-6$ years old and fed a standard diet based on green and cereal fodder, berseem, straw, and concentrated mixtures. Water was supplied constantly. The samples were acquired on a regular collection schedule using an artificial vagina and were immediately transferred to the laboratory. Subsequently, basic semen assessment was performed-volume $(\mathrm{mL}), \mathrm{pH}$, and concentration $\left(\times 10^{6} / \mathrm{mL}\right)$ were evaluated in each sample.
2.2. Spermatozoa Motility Analysis. Spermatozoa motility and progressive motility examinations were carried out using the Computer Assisted Semen Analysis (CASA) systemSpermVision (Minitube, Tiefenbach, Germany) with Olympus BX 51 phase contrast microscope (Olympus, Tokyo, Japan). The samples were placed into the Makler Counting Chamber (depth $10 \mu \mathrm{m}, 37 \pm 1^{\circ} \mathrm{C}$; Sefi Medical Instruments, Haifa, Israel) and immediately assessed. 1000 cells were evaluated in each sample [12].

2.3. Sample Processing. The samples were centrifuged (15 min, $10090 \times \mathrm{g}, 4^{\circ} \mathrm{C}$ ) to obtain the cell sediment and seminal plasma fraction. The fractions were separated, and seminal plasma was transferred into $1.5 \mathrm{~mL}$ tubes and kept frozen $\left(-80^{\circ} \mathrm{C}\right)$. The sediments were moved into tubes containing $1.5 \mathrm{~mL}$ distilled water and subsequently lysed via sonication for $40 \mathrm{sec}$ on ice. After sonication, the lysates were centrifuged $\left(15 \mathrm{~min}, 11828 \times \mathrm{g}, 4^{\circ} \mathrm{C}\right)$ to remove cell debris, and the supernatants involving the sperm cell content were transferred into $1.5 \mathrm{~mL}$ tubes and stored at $-80^{\circ} \mathrm{C}$ until further analysis [13].

2.4. Assessment of Chemical Elements. Both seminal plasma and cell lysates (at least $1 \mathrm{~mL}$ ) were mineralized by placing the samples in mineralization tubes, adding $2 \mathrm{~mL}$ of a nitric and perchloric acid mixture $\left(\mathrm{HNO}_{3}-\mathrm{HClO}_{4} ; 4: 1\right)$, and heating at $120^{\circ} \mathrm{C}$ for 65 minutes in a thermostat-controlled digestion block. The resulting solution was diluted to $10 \mathrm{~mL}$ with demineralized water. $\mathrm{Na}$ and $\mathrm{K}$ concentrations were determined by the voltammetric method (ASV) using an EA9C potentiostat model equipped with working CGMDE electrode, $\mathrm{AgCl}_{2}$, and platinum electrodes (MTM, Krakow, Poland). Concentrations of $\mathrm{Fe}, \mathrm{Cu}, \mathrm{Mg}$, and $\mathrm{Zn}$ were measured by flame absorption spectrophotometry (FAS) method with the Cole-Parmer 200A model (Cole-Parmer International, Court Vernon Hills, USA). Concentrations are expressed as $\mathrm{mg} / \mathrm{dL}$ [14].

2.5. Biochemical Studies. The measurements were based on a colorimetric reaction of the target substance and a subsequent UV/VIS spectrophotometric detection at a specific wavelength. SOD, CAT, GSH, and ALB were assessed using the Genesys 10 spectrophotometer (Thermo Fisher Scientific Inc., Waltham, USA). MDA content was analysed with the help of the Multiskan FC microplate photometer (Thermo Fisher Scientific Inc., Waltham, USA).

Before any of the prooxidant or antioxidant markers was examined, protein concentration was assessed using the DiaSys Total Protein (DiaSys, Holzheim, Germany) commercial kit. The measurement is based on the Biuret method. When $\mathrm{Cu}$ ions (copper sulphate) react with proteins to form a violet blue color complex in alkaline solution, the intensity of the color is directly proportional to the protein concentration and was measured at $540 \mathrm{~nm}$.

SOD activity was analyzed with the Randox RANSOD assay (Randox Laboratories, Crumlin, Great Britain). This method employs xanthine and xanthine oxidase (XOD) to generate superoxide radicals, which react with 2 -(4-iodophenyl)-3-(4-nitrophenol)-5-phenyltetrazolium chloride (I.N.T.) 
to form a red formazan dye. SOD activity was measured by the inhibition degree of this reaction at $505 \mathrm{~nm}$. The SOD activity is expressed as $\mathrm{U} / \mathrm{mg}$ protein.

CAT activity was assessed according to Beers Jr. and Sizer [15] by monitoring the decrease of $\mathrm{H}_{2} \mathrm{O}_{2}$ at $240 \mathrm{~nm}$. The calculation was based on the rate of $\mathrm{H}_{2} \mathrm{O}_{2}$ decomposition, which was proportional to the reduction of the absorbance during $1 \mathrm{~min}$. The values are expressed as $\mathrm{U} / \mathrm{mg}$ protein.

Reduced GSH was determined by the Ellman method [16]. The sample was treated with Ellman's reagent, which interacts with the thiol groups of GSH, cleaving the disulfide bond to give 2-nitro-5-thiobenzoate $\left(\mathrm{NTB}^{-}\right)$and creating the $\mathrm{NTB}^{2-}$ dianion in water at neutral and alkaline $\mathrm{pH}$. This ion has a yellow color and was quantified at $412 \mathrm{~nm}$. GSH concentration was expressed as $\mathrm{mg} / \mathrm{mg}$ protein.

ALB concentration was measured using the ALB BioLa Test (PLIVA-Lachema, Brno, Czech Republic) commercial kit and expressed as $\mathrm{mg} / \mathrm{mg}$ protein. The measurement was based on the reaction between ALB and Bromocresol Green at acid $\mathrm{pH}$ forming a complex, which was easy to detect photometrically at $578 \mathrm{~nm}$.

MDA content was detected with the help of the TBARS assay, modified for a 96-well plate and ELISA reader. The MDA-TBA product formed by the reaction of MDA and thiobarbituric acid (TBA) under high temperature (90$100^{\circ} \mathrm{C}$ ) and acidic conditions was measured at $530-540 \mathrm{~nm}$ [13]. The MDA concentration was expressed as $\mu \mathrm{M}$.

2.6. Statistical Analysis. All data were subjected to statistical analysis using the GraphPad Prism program (version 3.02 for Windows, GraphPad Software incorporated, San Diego, California, USA, http://www.graphpad.com/). Results are quoted as arithmetic mean \pm standard error of mean (SEM). Pearson product-moment correlation coefficient analysis for paired samples was used to assess correlations between all examined parameters. Additionally, the samples were categorized in three quality groups according to their motility rates. Comparative analysis of selected parameters in the seminal fractions as well as in the quality groups was carried out by one-way ANOVA with the Bonferroni multiple comparison test. The level of significance for the comparative as well as correlation analysis was set at ${ }^{* * *}(P<0.001) ;{ }^{* *}(P<0.01)$; ${ }^{*}(P<0.05)$.

\section{Results and Discussion}

Values of the basic seminal parameters are represented in Table 1. Animal donors and samples showed no signs of disease, infection, or pathology. Furthermore, results obtained from routine seminal evaluation met the standards and criteria established for the Simmental-Fleckvieh bovine breed, which is why we ruled out any impact of the health estate on the data obtained from further chemical and biochemical measurements.

Results of the FAS, ASV, and spectrophotometric analyses are shown in Table 2. The concentrations of the chemical elements recorded in both seminal fractions may be expressed in the following descending order: $\mathrm{Na}>\mathrm{K}>\mathrm{Zn}>\mathrm{Mg}>$
TABLE 1: Basic seminal and motility characteristics of the samples $(n=30)$.

\begin{tabular}{lc}
\hline Parameter & Mean \pm SEM \\
\hline Volume $[\mathrm{mL}]$ & $7.20 \pm 0.50$ \\
$\mathrm{pH}$ & $6.67 \pm 0.30$ \\
Concentration $\left[\times 10^{6}\right.$ cells $\left./ \mathrm{mL}\right]$ & $2995 \pm 40.50$ \\
Motility [\%] & $87.37 \pm 2.51$ \\
Progressive motility [\%] & $81.79 \pm 2.64$ \\
\hline
\end{tabular}

SEM: standard error of mean.

TABLE 2: Chemical and biochemical parameters of bovine seminal plasma and spermatozoa examined by the ASV and FAS methods (chemical elements) as well as UV/VIS spectrophotometry (prooxidant and antioxidant markers) $(n=30)$.

\begin{tabular}{lcc}
\hline Parameter & Seminal plasma & Cell lysates \\
\hline SOD [U/mg protein] & $0.49 \pm 0.03$ & $0.60 \pm 0.05$ \\
CAT [U/mg protein] & $1.19 \pm 0.10$ & $2.01 \pm 0.14^{* *}$ \\
GSH [mg/mg protein] & $0.10 \pm 0.02$ & $0.01 \pm 0.002^{* * *}$ \\
ALB [mg/mg protein] & $0.18 \pm 0.03$ & $0.10 \pm 0.005^{* *}$ \\
$\mathrm{MDA}[\mu \mathrm{M}]$ & $2.94 \pm 0.19$ & $13.29 \pm 0.67^{* * *}$ \\
$\mathrm{Na}[\mathrm{mg} / \mathrm{dL}]$ & $179.44 \pm 7.01$ & $141.11 \pm 3.02^{* *}$ \\
$\mathrm{~K}[\mathrm{mg} / \mathrm{dL}]$ & $25.97 \pm 2.10$ & $21.57 \pm 1.15$ \\
$\mathrm{Fe}[\mathrm{mg} / \mathrm{dL}]$ & $4.15 \pm 0.54$ & $2.02 \pm 0.30^{* *}$ \\
$\mathrm{Cu}[\mathrm{mg} / \mathrm{dL}]$ & $2.39 \pm 0.27$ & $1.15 \pm 0.15^{* *}$ \\
$\mathrm{Mg}[\mathrm{mg} / \mathrm{dL}]$ & $7.65 \pm 0.90$ & $2.03 \pm 0.19^{* *}$ \\
$\mathrm{Zn}[\mathrm{mg} / \mathrm{dL}]$ & $23.59 \pm 2.05$ & $9.40 \pm 1.10^{* *}$ \\
\hline
\end{tabular}

Mean \pm SEM. ${ }^{* *} P<0.01 ;{ }^{* * *} P<0.001$. SOD: superoxide dismutase; CAT: catalase; GSH: glutathione; ALB: albumin; MDA: malondialdehyde; Na: sodium; K: potassium; Fe: iron; $\mathrm{Cu}$ : copper; $\mathrm{Mg}$ : magnesium; $\mathrm{Zn}$ : zinc.

$\mathrm{Fe}>\mathrm{Cu}[\mathrm{mg} / \mathrm{dL}]$. While the outcomes of the ASV and FAS examinations of the seminal plasma suggest that the concentrations of all elements were within the physiological limits and comparable to the results of other authors $[4,17-$ 19], their concentrations, except for $\mathrm{K}$, were significantly $(P<$ 0.001 ) lower in the spermatozoa lysates. As we found no data available to compare and discuss our detected statistical differences, we assume that unlike the blood plasma, the seminal plasma does not have a proper filtration system and therefore acts as an accumulator of any organic or inorganic substance. At the same time, lower concentrations of chemical elements in the sperm cells prove that spermatozoa lack a typical cytoplasm as a source of potential binding molecules for the minerals. Nonetheless, we have to be aware of the fact that the content of chemical elements within spermatozoa may vary and is highly dependent on the concentration of the sperm cell within the ejaculate.

The seminal plasma is considered to be the central source of antioxidants protecting the seminal components against oxidative damage [10]. Our records agree showing that the LPO expressed as the amount of MDA was significantly higher in the sperm lysates when compared to the seminal plasma $(P<0.001$; Table 2$)$, suggesting that the spermatozoa lipids are the primary target for FR, while the seminal plasma lipids may be protected by a complex antioxidant system [20]. At the same time, concentrations of GSH and ALB as 
TABLE 3: Correlations between motility parameters, prooxidant/antioxidant markers, and chemical elements in bovine seminal plasma evaluated by the Pearson product-moment correlation $(n=30)$.

\begin{tabular}{|c|c|c|c|c|c|c|c|c|c|c|c|c|c|}
\hline & MOT & PROG & SOD & CAT & GSH & ALB & MDA & $\mathrm{Na}$ & $\mathrm{K}$ & $\mathrm{Cu}$ & $\mathrm{Fe}$ & $\mathrm{Mg}$ & $\mathrm{Zn}$ \\
\hline MOT & 1 & & & & & & & & & & & & \\
\hline PROG & $0.972^{* * *}$ & 1 & & & & & & & & & & & \\
\hline SOD & $0.583^{* *}$ & $0.601^{* * *}$ & 1 & & & & & & & & & & \\
\hline CAT & $0.396^{*}$ & $0.400^{*}$ & $0.722^{* * *}$ & 1 & & & & & & & & & \\
\hline GSH & $0.440^{*}$ & $0.452^{* *}$ & $0.530^{* *}$ & $0.410^{*}$ & 1 & & & & & & & & \\
\hline ALB & $0.407^{*}$ & $0.422^{*}$ & $0.435^{*}$ & $0.415^{*}$ & 0.210 & 1 & & & & & & & \\
\hline MDA & $-0.528^{* *}$ & $-0.545^{* *}$ & $-0.612^{* *}$ & $-0.623^{* *}$ & $-0.530^{* *}$ & $-0.351^{*}$ & 1 & & & & & & \\
\hline $\mathrm{Na}$ & $0.312^{*}$ & $0.328^{*}$ & 0.315 & 0.304 & 0.318 & $0.392^{*}$ & $-0.365^{*}$ & 1 & & & & & \\
\hline $\mathrm{K}$ & $-0.387^{*}$ & $-0.398^{*}$ & $-0.400^{*}$ & -0.209 & $-0.445^{*}$ & $-0.365^{*}$ & $0.346^{*}$ & -0.297 & 1 & & & & \\
\hline $\mathrm{Cu}$ & $0.423^{*}$ & $0.441^{* *}$ & $0.499^{* *}$ & $0.451^{*}$ & $0.439^{*}$ & $0.392^{*}$ & $-0.362^{*}$ & $0.388^{*}$ & -0.305 & 1 & & & \\
\hline $\mathrm{Fe}$ & $0.429^{* *}$ & $0.464^{* *}$ & $0.470^{* *}$ & $0.569^{* *}$ & $0.359^{*}$ & $0.445^{* *}$ & $-0.360^{*}$ & $0.390^{*}$ & $-0.331^{*}$ & $0.495^{* *}$ & 1 & & \\
\hline $\mathrm{Mg}$ & $0.498^{* *}$ & $0.510^{* *}$ & $0.475^{* *}$ & $0.423^{*}$ & $0.414^{* *}$ & $0.381^{*}$ & $-0.360^{*}$ & $0.425^{*}$ & -0.215 & $0.413^{*}$ & $0.422^{*}$ & 1 & \\
\hline $\mathrm{Zn}$ & $0.559^{* *}$ & $0.578^{* *}$ & $0.532^{* *}$ & $0.399^{*}$ & $0.452^{*}$ & $0.439^{*}$ & $-0.482^{* *}$ & 0.307 & -0.305 & $0.331^{*}$ & $0.335^{*}$ & $0.408^{*}$ & 1 \\
\hline
\end{tabular}

The interpretation of the results was based on the value of the correlation coefficient: $\pm 0.111- \pm 0.333$ : low correlation; $\pm 0.334- \pm 0.666$ : moderate correlation; $\pm 0.667- \pm 0.999$ : high correlation. ${ }^{*} P<0.05 ;{ }^{* *} P<0.01 ;{ }^{* *} P<0.001$. MOT: spermatozoa motility [\%]; PROG: spermatozoa progressive motility [\%]; SOD: superoxide dismutase [U/mg protein]; CAT: catalase [U/mg protein]; GSH: glutathione [mg/mg protein]; ALB: albumin [mg/mg protein]; MDA: malondialdehyde $[\mu \mathrm{M}]$; Na: sodium [mg/dL]; K: potassium [mg/dL]; Fe: iron [mg/dL]; Cu: copper [mg/dL]; Mg: magnesium [mg/dL]; Zn: zinc [mg/dL].

important FR trapping molecules were significantly lower in the cell lysates $(P<0.001$; Table 2$)$, proving that the nonenzymatic antioxidant system of the sperm cell is weak and unfavourable [10]. On the other hand, the activity of both antioxidant enzymes was higher in the cell lysates when compared to the seminal plasma $(P>0.05$ for SOD and $P<0.01$ for CAT, resp., Table 2). We assume that even though the overall concentration and variability of antioxidants in spermatozoa are lower, their activities may be considerably higher in order to compensate for the lack of antioxidant diversity.

Tables 3 and 4 display the results of the correlation analysis between the selected motility parameters, biochemical markers, and minerals quantified in bovine seminal plasma and spermatozoa. MOT and PROG as the basic characteristics of spermatozoa viability were significantly $(P<0.05 ; P<0.01 ; P<0.001)$ positively correlated with all the enzymatic as well as nonenzymatic antioxidants of both seminal fractions. Inversely, MDA was significantly $(P<0.05 ; P<0.01 ; P<0.001)$ negatively correlated with the motility as well as antioxidant characteristics of the seminal plasma and spermatozoa samples.

The analysis shows that $\mathrm{Na}, \mathrm{Cu}, \mathrm{Fe}, \mathrm{Mg}$, and $\mathrm{Zn}$ exhibited positive correlations of various significance with all the motility and antioxidant parameters, as well as significant negative correlations with MDA $(P<0.05 ; P<0.01)$ in both seminal fractions. Differently, $\mathrm{K}$ displayed negative correlations with the seminal and antioxidant characteristics $(P<0.05)$. At the same time, a positive and significant correlation was recorded between $\mathrm{K}$ and MDA $(P<0.05)$ in the seminal plasma as well as spermatozoa (Tables 3 and 4).

To have a better understanding of the results, the samples were categorized in three groups of excellent (Ex; >90\% motile; $n=11$ ), good (Go; $80-90 \%$ motile; $n=12$ ) and moderate (Mo; $<80 \%$ motile; $n=7$ ) quality according to their motility rates (Tables 5 and 6). Mean values for MOT and PROG were significantly different between the groups $(P<0.05 ; P<0.001)$. The highest SOD, CAT, ALB, and GSH values together with the lowest MDA concentration were recorded in the Ex group of both seminal fractions. Inversely, the lowest antioxidant activity but the highest MDA content was detected in the Mo group (Tables 5 and 6). Significant differences $(P<0.05 ; P<0.01)$ were observed when comparing the prooxidant and antioxidant parameters between the Ex and the Mo groups.

The highest contents of $\mathrm{Fe}, \mathrm{Cu}, \mathrm{Mg}$, and $\mathrm{Zn}$ were recorded in the Ex group; the Mo group exhibited the lowest concentrations of the elements. The highest $\mathrm{K}$ content was detected in the Mo group, while its concentration was significantly lower in the Ex group $(P<0.01)$. No significant changes in the $\mathrm{Na}$ concentration were detected in the quality groups; however, its highest concentration was revealed in the Ex group, while its lowest concentration was recorded in the Go group.

Our correlation and comparative examinations on typical antioxidants (SOD, CAT, and GSH) confirm their positive effects on spermatozoa motility and quality as well as antioxidant profile concluded in different studies $[4,13,21-24]$ and confirm that decreased concentrations and/or activities of FR scavenging molecules are related to a decreased quality, viability, and fertilization potential of semen accompanied by an increased risk of seminal oxidative stress development. Interestingly, ALB, which is not considered to be a dominant protein of the bovine ejaculate [25], exhibited detectable and important concentrations in both seminal plasma and spermatozoa (Table 2). Moreover, positive relationships between ALB, spermatozoa motility, and antioxidant profile confirms the suggestions of Bourdon and Blache [26] as well as Tvrdá et al. [21] that ALB could be an important seminal antioxidant protein acting through its multiple-binding sites and free radical-trapping properties.

Numerous literature sources indicate that LPO could be a primary cause of a decreased seminal quality in fertility disorders [13, 20, 24, 27]. Results of our study demonstrate 
TABLE 4: Correlations between motility parameters, prooxidant/antioxidant markers, and chemical elements in bovine spermatozoa evaluated by the Pearson product-moment correlation $(n=30)$.

\begin{tabular}{|c|c|c|c|c|c|c|c|c|c|c|c|c|c|}
\hline & MOT & PROG & SOD & CAT & GSH & ALB & MDA & $\mathrm{Na}$ & $\mathrm{K}$ & $\mathrm{Cu}$ & $\mathrm{Fe}$ & $\mathrm{Mg}$ & $\mathrm{Zn}$ \\
\hline MOT & 1 & & & & & & & & & & & & \\
\hline PROG & $0.972^{* * *}$ & 1 & & & & & & & & & & & \\
\hline SOD & $0.620^{* * *}$ & $0.642^{* * *}$ & 1 & & & & & & & & & & \\
\hline CAT & $0.425^{*}$ & $0.440^{*}$ & $0.789^{* * *}$ & 1 & & & & & & & & & \\
\hline GSH & $0.482^{* *}$ & $0.498^{* *}$ & $0.585^{* *}$ & $0.468^{*}$ & 1 & & & & & & & & \\
\hline ALB & $0.437^{*}$ & $0.450^{*}$ & $0.461^{*}$ & $0.430^{*}$ & 0.251 & 1 & & & & & & & \\
\hline MDA & $-0.520^{* *}$ & $-0.539^{* *}$ & $-0.699^{* * *}$ & $-0.672^{* * *}$ & $-0.589^{* * *}$ & $-0.461^{*}$ & 1 & & & & & & \\
\hline $\mathrm{Na}$ & $0.345^{*}$ & $0.359^{*}$ & $0.355^{*}$ & $0.349^{*}$ & $0.339^{*}$ & 0.322 & $-0.359^{*}$ & 1 & & & & & \\
\hline $\mathrm{K}$ & $-0.422^{* *}$ & $-0.436^{* *}$ & $-0.439^{*}$ & -0.245 & $-0.452^{*}$ & $-0.366^{*}$ & $0.336^{*}$ & -0.310 & 1 & & & & \\
\hline $\mathrm{Cu}$ & $0.440^{*}$ & $0.454^{* *}$ & $0.502^{* *}$ & $0.450^{*}$ & $0.449^{*}$ & $0.409^{*}$ & $-0.380^{*}$ & $0.376^{*}$ & -0.311 & 1 & & & \\
\hline $\mathrm{Fe}$ & $0.474^{* *}$ & $0.493^{* *}$ & $0.469^{* *}$ & $0.563^{* *}$ & $0.369^{*}$ & $0.492^{* *}$ & $-0.371^{*}$ & $0.400^{*}$ & $-0.375^{* *}$ & $0.417^{*}$ & 1 & & \\
\hline $\mathrm{Mg}$ & $0.505^{* *}$ & $0.532^{* *}$ & $0.512^{* *}$ & $0.419^{*}$ & $0.425^{* *}$ & $0.415^{*}$ & $-0.392^{*}$ & $0.452^{* *}$ & -0.236 & $0.433^{*}$ & $0.369^{*}$ & 1 & \\
\hline $\mathrm{Zn}$ & $0.565^{* *}$ & $0.590^{* *}$ & $0.542^{* *}$ & $0.454^{*}$ & $0.474^{*}$ & $0.439^{*}$ & $-0.495^{* *}$ & $0.329^{*}$ & $-0.367^{*}$ & $0.379^{*}$ & $0.333^{*}$ & $0.415^{*}$ & 1 \\
\hline
\end{tabular}

The interpretation of the results was based on the value of the correlation coefficient: $\pm 0.111- \pm 0.333$ : low correlation; $\pm 0.334- \pm 0.666$ : moderate correlation; $\pm 0.667- \pm 0.999$ : high correlation. ${ }^{*} P<0.05 ;{ }^{* *} P<0.01 ;{ }^{* * *} P<0.001$. MOT: spermatozoa motility [\%]; PROG: spermatozoa progressive motility [\%]; SOD: superoxide dismutase [U/mg protein]; CAT: catalase [U/mg protein]; GSH: glutathione [mg/mg protein]; ALB: albumin [mg/mg protein]; MDA: malondialdehyde $[\mu \mathrm{M}]$; Na: sodium [mg/dL]; K: potassium [mg/dL]; Fe: iron [mg/dL]; Cu: copper [mg/dL]; Mg: magnesium [mg/dL]; Zn: zinc [mg/dL].

TABLE 5: Average values of seminal motility parameters, prooxidant/antioxidant markers, and chemical elements in bovine seminal plasma quality groups (Mean \pm SEM) and Bonferroni multiple comparison test results.

\begin{tabular}{lccc}
\hline & Ex $(n=11)$ & Go $(n=12)$ & Mo $(n=7)$ \\
\hline MOT [\%] & $93.75 \pm 4.50$ & $85.63 \pm 3.88^{* \mathrm{a}}$ & $63.20 \pm 3.99^{* * * \mathrm{~b} ; * * * \mathrm{c}}$ \\
PROG [\%] & $90.67 \pm 4.57$ & $81.75 \pm 1.33^{* \mathrm{a}}$ & $59.33 \pm 6.01^{* * * \mathrm{~b} ; * * * \mathrm{c}}$ \\
SOD [U/mg & $0.68 \pm 0.04$ & $0.51 \pm 0.05$ & $0.31 \pm 0.05^{* * \mathrm{~b} ; * \mathrm{c}}$ \\
protein] & & & \\
CAT [U/mg & $1.59 \pm 0.04$ & $1.28 \pm 0.03$ & $1.10 \pm 0.02$ \\
of protein] & & & \\
GSH [mg/mg & $0.12 \pm 0.06$ & $0.08 \pm 0.007$ & $0.06 \pm 0.006^{* \mathrm{~b}}$ \\
of protein] & & & \\
ALB [mg/mg & $0.23 \pm 0.04$ & $0.18 \pm 0.05$ & $0.17 \pm 0.03$ \\
of protein] & & & \\
$\mathrm{MDA}[\mu \mathrm{M}]$ & $1.54 \pm 0.37$ & $2.18 \pm 0.15$ & $2.96 \pm 0.46^{* \mathrm{~b}}$ \\
$\mathrm{Na}[\mathrm{mg} / \mathrm{dL}]$ & $189.60 \pm 5.76$ & $164.40 \pm 4.33$ & $183.60 \pm 5.87$ \\
$\mathrm{~K}[\mathrm{mg} / \mathrm{dL}]$ & $23.10 \pm 4.90$ & $29.40 \pm 5.13$ & $31.50 \pm 4.45^{* \mathrm{~b}}$ \\
$\mathrm{Fe}[\mathrm{mg} / \mathrm{dL}]$ & $4.09 \pm 0.86$ & $3.74 \pm 0.61$ & $3.39 \pm 0.84$ \\
$\mathrm{Cu}[\mathrm{mg} / \mathrm{dL}]$ & $2.37 \pm 0.08$ & $2.12 \pm 0.08$ & $2.05 \pm 0.22$ \\
$\mathrm{Mg}[\mathrm{mg} / \mathrm{dL}]$ & $8.62 \pm 1.03$ & $7.29 \pm 0.98$ & $5.72 \pm 0.97^{* * \mathrm{~b}}$ \\
$\mathrm{Zn}[\mathrm{mg} / \mathrm{dL}]$ & $29.07 \pm 2.08$ & $21.76 \pm 2.12^{* \mathrm{a}}$ & $15.63 \pm 2.10^{* * \mathrm{~b}}$ \\
\hline
\end{tabular}

ax versus Go; ${ }^{\mathrm{b}}$ Ex versus Mo; ${ }^{\mathrm{c}} \mathrm{Go}$ versus Mo. ${ }^{*} P<0.05 ;{ }^{* *} P<0.01$; ${ }^{* * *} P<0.001$. Quality groups are based on the motility values: excellent quality ( $>90 \%$ motile), good quality ( $80-89 \%$ motile), and moderate quality (<79\% motile). MOT: motility; PROG: progressive motility; SOD: superoxide dismutase; CAT: catalase; ALB: albumin; GSH: glutathione; MDA: malondialdehyde; Na: Sodium; K: potassium; Fe: iron; $\mathrm{Cu}$ : copper, $\mathrm{Mg}$ : magnesium; Zn: zinc.

that the concentration of MDA, a specific marker of LPO, was significantly higher in the low quality seminal fractions and suggest that the activity of oxygen radicals in these samples was the most detrimental (Tables 5 and 6). In addition, our
TABLE 6: Average values of seminal motility parameters, prooxidant/antioxidant markers, and chemical elements in bovine spermatozoa quality groups (Mean \pm SEM) and Bonferroni multiple comparison test results.

\begin{tabular}{lccc}
\hline & Ex $(n=11)$ & Go $(n=12)$ & Mo $(n=7)$ \\
\hline MOT [\%] & $93.75 \pm 4.50$ & $85.63 \pm 3.88^{* \mathrm{a}}$ & $63.20 \pm 3.99^{* * * \mathrm{~b} ; * * \mathrm{c}}$ \\
PROG [\%] & $90.67 \pm 4.57$ & $81.75 \pm 1.33^{* \mathrm{a}}$ & $59.33 \pm 6.01^{* * * \mathrm{~b} ; * * \mathrm{c}}$ \\
SOD [U/mg & $0.78 \pm 0.07$ & $0.65 \pm 0.06$ & $0.40 \pm 0.07^{* * \mathrm{~b} ; * \mathrm{c}}$ \\
protein] & & & \\
CAT [U/mg of & $2.37 \pm 0.24$ & $2.05 \pm 0.23$ & $1.65 \pm 0.25^{* \mathrm{~b}}$ \\
protein] & & & \\
GSH [mg/mg & $0.02 \pm 0.006$ & $0.01 \pm 0.007$ & $0.005 \pm 0.001^{* \mathrm{~b}}$ \\
of protein] & & & \\
ALB [mg/mg & $0.13 \pm 0.04$ & $0.09 \pm 0.005$ & $0.06 \pm 0.005^{* \mathrm{~b}}$ \\
of protein] & & & \\
$\mathrm{MDA}[\mu \mathrm{M}]$ & $8.74 \pm 1.17$ & $14.10 \pm 1.15^{* \mathrm{a}}$ & $16.46 \pm 1.36^{* * \mathrm{~b} ; * \mathrm{c}}$ \\
$\mathrm{Na}[\mathrm{mg} / \mathrm{dL}]$ & $129.60 \pm 4.76$ & $114.35 \pm 4.33$ & $126.93 \pm 4.87$ \\
$\mathrm{~K}[\mathrm{mg} / \mathrm{dL}]$ & $18.10 \pm 2.90$ & $23.95 \pm 3.13$ & $30.79 \pm 3.45^{* * \mathrm{~b} ; * \mathrm{c}}$ \\
$\mathrm{Fe}[\mathrm{mg} / \mathrm{dL}]$ & $2.39 \pm 0.86$ & $2.09 \pm 0.61$ & $1.51 \pm 0.21^{* \mathrm{~b}}$ \\
$\mathrm{Cu}[\mathrm{mg} / \mathrm{dL}]$ & $1.37 \pm 0.12$ & $1.02 \pm 0.10$ & $0.80 \pm 0.09^{* \mathrm{~b}}$ \\
$\mathrm{Mg}[\mathrm{mg} / \mathrm{dL}]$ & $2.65 \pm 0.50$ & $1.99 \pm 0.40$ & $1.49 \pm 0.27^{* \mathrm{~b}}$ \\
$\mathrm{Zn}[\mathrm{mg} / \mathrm{dL}]$ & $15.07 \pm 2.08$ & $10.76 \pm 1.13^{* \mathrm{a}}$ & $7.63 \pm 0.926^{* * \mathrm{~b}}$ \\
\hline
\end{tabular}

ax versus Go; ${ }^{\mathrm{b}}$ Ex versus Mo; ${ }^{\mathrm{c}} \mathrm{Go}$ versus Mo. ${ }^{*} P<0.05 ;{ }^{* *} P<0.01$; ${ }^{* * *} P<0.001$. Quality groups are based on the motility values: excellent quality ( $>90 \%$ motile), good quality ( $80-89 \%$ motile), and moderate quality (<79\% motile). MOT: motility; PROG: progressive motility; SOD: superoxide dismutase; CAT: catalase; ALB: albumin; GSH: glutathione; MDA: malondialdehyde; Na: Sodium; K: potassium; Fe: iron; $\mathrm{Cu}$ : copper, $\mathrm{Mg}$ : magnesium; Zn: zinc.

outcomes agree with Tavilani et al. [27] demonstrating strong negative associations between the specific activities of antioxidant enzymes with the MDA content. These observations 
suggest that seminal CAT and SOD play a significant role in the protection against LPO in ejaculates.

Semen quality as well as the ability of spermatozoa to undergo capacitation, acrosome reaction, and oocyte fusion is crucial phenomenon intimately related to the antioxidant and mineral profile of the organism. At the same time, seminal chemical elements are directly or indirectly involved in the protection against OS or its modification, induction of changes in the activity of spermatozoa, or interactions with other substances [1].

Despite the fact that $\mathrm{Na}$ and $\mathrm{K}$ are reported to be indirectly responsible for the maintenance of seminal osmolarity and activity [6], our examinations revealed that while $\mathrm{Na}$ exhibited generally favorable effects on the seminal quality and antioxidant balance, $\mathrm{K}$ behaved inversely. Gür and Demirci [17] detected a positive impact of $\mathrm{Na}$ on all spermatozoa vitality characteristics assuming that $\mathrm{Na}$ is crucial for proper physicochemical properties of semen. Our results agree and furthermore conclude that the seminal $\mathrm{Na}$ is indispensable for a suitable antioxidant milieu and activity. On the other hand, negative associations between the $\mathrm{K}$ concentration, MOT, and PROG (Tables 3 and 4) agree with Gür and Demirci [17] as well as Sheth and Rao [28], proposing that oxygen uptake, glycolysis, and fructolysis could be inhibited by $\mathrm{K}$ and indicating that this element may adversely affect spermatozoa activity. Moreover, negative correlations together with high concentrations of $\mathrm{K}$ in the Mo groups (Tables 5 and 6) confirm the suggestions of Ford [9] and Griveau et al. [29] that at low $\mathrm{pH}$ the $\mathrm{K}^{+}$ion pairs with the superoxide causing a significant increase in LPO and FR formation, which are inversely correlated with sperm motility and antioxidant status, especially with SOD and GSH (Tables 3 and 4 ), which are directly responsible for superoxide scavenging [11].

$\mathrm{Fe}$ and $\mathrm{Cu}$ deficiencies represent the most common nutritional problems existing today and are correlated with impaired development and reproductive performance [30]. At the same time, prolonged intake of high doses of both metals may lead to pathological conditions. According to Massányi et al. [3], increased Fe concentration may bear negatively on spermatozoa viability and morphology. Other studies show that mean Fe concentration in seminal plasma was highly associated with sperm progressive motility, gross motility, and viability $[18,31]$. Moreover, $\mathrm{Fe}$ is integral for catalase, and it has been reported that the CAT activity may be significantly reduced as a result of iron deficiency [32], which explains significant positive associations between Fe and CAT in both seminal fractions (Tables 3 and 4). Incubation of spermatozoa in the presence of $\mathrm{Cu}$ had a negative effect on the motility parameters examined by the CASA system in studies by Roychoudhury et al. [8] and Tvrdá et al. [33]. On the contrary, other authors report positive effects of $\mathrm{Cu}$ on the sperm count, motility, and progressive motility as well as on the prevention of LPO via the activity of SOD and CAT $[4,31,34]$. Significant positive associations between the seminal plasma $\mathrm{Cu}$ and SOD confirm that $\mathrm{Cu}$ is essential for a proper activation of the $\mathrm{Cu} / \mathrm{Zn} \mathrm{SOD}$ isoenzyme increasing the number of normal and healthy sperm cells $[30,34]$. Differences in the $\mathrm{Cu}$ and $\mathrm{Fe}$ amounts in the quality groups
(Tables 5 and 6) suggest that physiological concentrations of both trace elements may have a stimulating impact on both motility as well as antioxidant status of bovine semen.

Positive associations between $\mathrm{Mg}$, motility, and antioxidant markers detected in our study are in accordance with Abdul-Rasheed [35] and Eghbali et al. [36]. As shown by Chandra et al. [37], Mg intake decreased LPO and increased SOD as well as CAT activity in rat testicular tissue. Additionally, it has been reported that semen contains secretory granules and vesicles of prostatic origin and containing $\mathrm{Mg}$ dependent ATPase, which might have a regulatory effect on sperm motility by modulating the concentration of essential cations in the seminal environment [38]. Furthermore, significant correlations between $\mathrm{Mg}$ and GSH (Tables 3 and 4) may be explained by the fact that GSH is Mg-dependent, as the glutathione synthetase needs $\mathrm{Mg}^{2+}$ cations to get activated [39].

Zn levels in seminal plasma have been positively associated with sperm concentration and motility in some studies [40, 41], while nonsignificant to negative correlations have been found in others $[42,43]$. Our analysis revealed a significant positive effect of $\mathrm{Zn}$ on both spermatozoa motility parameters, as well as antioxidant markers, most significantly with SOD (Tables 3 and 4). The cytosolic $\mathrm{Cu} / \mathrm{Zn}$ SOD is the major SOD isoenzyme found in seminal plasma as well as spermatozoa [11], which additionally explains positive correlations between $\mathrm{Zn}$ and $\mathrm{Cu}$ (Tables 3 and 4). Increased FR in infertile males have been previously associated with a decrease of seminal $\mathrm{Zn}$ content, arising their harmful effects on the sperm cells which are subsequently linked to abnormal seminal parameters [44], and increase in the oxidation of lipids, DNA, and proteins, causing the loss of spermatozoa membrane integrity [45]. Negative associations between $\mathrm{Zn}$ and MDA (Tables 3 and 4), as well as a significant decline of $\mathrm{Zn}$ in the quality groups (Tables 5 and 6 ), may therefore support the evidence defending the antioxidant capacity of seminal Zn.

\section{Conclusions}

In conclusion, our study presents a complex intercellular and intracellular network of interactions and associations between the mineral elements, markers of spermatozoa quality, and antioxidant profile within the bovine semen. At the same time our results indicate that any mineral imbalance in seminal plasma or spermatozoa may have a negative impact on seminal abnormalities and/or oxidative stress development and therefore may be considered as a risk factor for male fertility complications. At last, we suggest that routine evaluation of chemical composition and antioxidant status of both seminal fractions should become established and standardized for fertility assessment in veterinary practice.

\section{Conflict of Interests}

The authors declare that they have no conflict of interests. The authors alone are responsible for the content and writing of the paper. 


\section{Acknowledgments}

This work was supported by the research projects of the Cultural and Educational Grant Agency of the Ministry of Education, Science, Research and Sport of the Slovak Republic (KEGA no. 013SPU-4/2012), the Scientific Grant Agency of the Ministry of Education, Science, Research and Sport of the Slovak Republic (VEGA no. 1/0532/11), the Slovak Research and Development Agency (APVV no. SKHU-000508 ) and by the European Community under the project no. 26220220180: "Construction of the "AgroBioTech" Research Centre".

\section{References}

[1] U. Marzec-Wróblewska, P. Kamiński, and P. ŁaKota, "Influence of chemical elements on mammalian spermatozoa," Folia Biologica, vol. 58, pp. 7-12, 2012.

[2] P. Massányi, J. Trandžík, P. Nad' et al., “Concentration of copper, iron, zinc, cadmium, lead and nickel in boar semen and relation to the spermatozoa quality," Journal of Environmental Science and Health A, vol. 38, pp. 2634-2651, 2003.

[3] P. Massányi, J. Trandžík, P. Nad' et al., "Concentration of copper, iron, zinc, cadmium, lead and nickel in bull and ram semen and relation to the occurence of pathological spermatozoa," Journal of Environmental Science and Health A, vol. 39, pp. 3005-3014, 2004.

[4] M. Eghbali, S. M. Alavi-Shoushtari, and S. Asri Rezaii, "Effects of copper and superoxide dismutase content of seminal plasma on buffalo semen characteristics," Pakistan Journal of Biological Sciences, vol. 11, no. 15, pp. 1964-1968, 2008.

[5] F. Atig, M. Raffa, H. Ben-Ali, A. Kerkeni, A. Saad, and A. Mounir, "Impact of seminal trace element and glutathione levels on semen quality of Tunisian infertile men," BMC Urology, vol. 12, pp. 6-14, 2012.

[6] P. Massanyi, J. Weis, N. Lukac, J. Trandzik, and J. Bystricka, "Cadmium, zinc, copper, sodium and potassium concentrations in rooster and turkey semen and their correlation," Journal of Environmental Science and Health A, vol. 43, no. 5, pp. 563-565, 2008.

[7] M. B. Sørensen, I. A. Bergdahl, N. H. I. Hjøllund, J. P. E. Bonde, M. Stoltenberg, and E. Ernst, "Zinc, magnesium and calcium in human seminal fluid: relations to other semen parameters and fertility," Molecular Human Reproduction, vol. 5, no. 4, pp. 331337, 1999.

[8] S. Roychoudhury, J. Slivková, J. Bulla, and P. Massányi, “Copper administration alerts fine parameters of spermatozoa motility in vitro," Folia Veterinaria, vol. 52, pp. 64-68, 2008.

[9] W. C. L. Ford, "Reactive oxygen species and sperm," Human Fertility, vol. 4, no. 2, pp. 77-78, 2001.

[10] A. Agarwal, K. P. Nallella, S. S. Allamaneni, and T. M. Said, "Role of antioxidants in treatment of male infertility: an overview of the literature," Reproductive BioMedicine Online, vol. 8, no. 6, pp. 616-627, 2004.

[11] E. Tvrdá, Z. Kňažická, L. Bárdos, P. Massányi, and N. Lukáč, "Impact of oxidative stress on male fertility-a review," Acta Veterinaria Hungarica, vol. 59, pp. 465-484, 2011.

[12] Massanyi, P. Chrenek, N. Lukac et al., "Comparison of different evaluation chambers for analysis of rabbit spermatozoa motility using CASA system," Slovak Journal of Animal Science, vol. 41, pp. 60-66, 2008.
[13] E. Tvrdá, Z. Kňažická, J. Lukáčová et al., “The impact of lead and cadmium on selected motility, prooxidant and antioxidant parameters of bovine seminal plasma and spermatozoa," Journal of Environmental Science and Health A, vol. 48, pp. 1-9, 2013.

[14] N. Lukáč, P. Massányi, J. Kročková et al., "Relationship between trace element concentrations and spermatozoa quality in rabbit semen," Slovak Journal of Animal Science, vol. 42, pp. 46-50, 2009.

[15] R. F. Beers Jr. and I. W. Sizer, "A spectrophotometric method for measuring the breakdown of hydrogen peroxide by catalase," The Journal of Biological Chemistry, vol. 195, no. 1, pp. 133-140, 1952.

[16] G. L. Ellman, “Tissue sulfhydryl groups”, Archives of Biochemistry and Biophysics, vol. 82, no. 1, pp. 70-77, 1959.

[17] S. Gür and E. Demirci, "Effect of calcium, magnesium, sodium and potassium levels in seminal plasma of holstein bulls on spermatological character," Turkish Journal of Veterinary and Animal Sciences, vol. 24, no. 3, pp. 275-281, 2000.

[18] R. G. Cragle, G. W. Salisbury, and J. H. Muntz, "Distribution of bulk and trace minerals in bull reproductive tract fluid and semen," Journal of Dairy Science, vol. 41, pp. 1273-1277, 1958.

[19] M. Çevik, P. B. Tuncer, U. Taşdemir, and T. Özgürtaş, "Comparison of spermatological characteristics and biochemical seminal plasma parameters of normozoospermic and oligoasthenozoospermic bulls of two breeds," Turkish Journal of Veterinary and Animal Sciences, vol. 31, no. 6, pp. 381-387, 2007.

[20] M. L. Selley, M. J. Lacey, M. R. Bartlett, C. M. Copeland, and N. G. Ardlie, "Content of significant amounts of a cytotoxic end-product of lipid peroxidation in human semen," Journal of Reproduction and Fertility, vol. 92, no. 2, pp. 291-298, 1991.

[21] E. Tvrdá, Z. Kňažická, and N. Lukac, "Selected heavy metals versus antioxidant parameters in bull seminal plasma-a comparative study," Journal of Environmental Science and Health A, vol. 47, pp. 1261-1266, 2012.

[22] I. Alkan, F. Simsek, G. Haklar et al., "Reactive oxygen species production by the spermatozoa of patients with idiopathic infertility: relationship to seminal plasma antioxidants," The Journal of Urology, vol. 157, pp. 140-143, 1997.

[23] S. Eskiocak, A. S. Gozen, S. B. Yapar, F. Tavas, A. S. Kilic, and M. Eskiocak, "Glutathione and free sulphydryl content of seminal plasma in healthy medical students during and after exam stress," Human Reproduction, vol. 20, no. 9, pp. 25952600, 2005.

[24] A. Agarwal, I. Ikemoto, and K. R. Loughlin, "Relationship of sperm parameters with levels of reactive oxygen species in semen specimens," The Journal of Urology, vol. 152, no. 1, pp. 107-110, 1994.

[25] T. Chard, J. Parslow, T. Rehmann, and A. Dawnay, "The concentrations of transferrin, beta-microglobulin, and albumin in seminal plasma in relation to sperm count," Fertility and Sterility, vol. 55, pp. 211-213, 1991.

[26] E. Bourdon and D. Blache, "The importance of proteins in defense against oxidation," Antioxidants and Redox Signaling, vol. 3, no. 2, pp. 293-311, 2001.

[27] H. Tavilani, M. T. Goodarzi, A. Vaisi-Raygani, S. Salimi, and T. Hassanzadeh, "Activity of antioxidant enzymes in seminal plasma and their relationship with lipid peroxidation of spermatozoa," International Brazilian Journal of Urology, vol. 34, no. 4, pp. 485-491, 2008.

[28] A. Sheth and S. Rao, "Potassium levels in human semen with reference to sperm motility," Experientia, vol. 18, no. 7, pp. 324$325,1962$. 
[29] J. F. Griveau, P. Renard, and D. Le Lannou, "An in vitro promoting role for hydrogen peroxide in human sperm capacitation," International Journal of Andrology, vol. 17, no. 6, pp. 300-307, 1994.

[30] P. Sharp, "The molecular basis of copper and iron interactions," Proceedings of the Nutrition Society, vol. 63, no. 4, pp. 563-569, 2004.

[31] M. Eghbali, S. M. Alavi-Shoushtari, S. Asri-Rezai, and M. H. K. Ansari, "Effects of the seminal plasma iron and lead content on semen quality of Water Buffalo (Bubalus bubalis) bulls," Veterinary Research Forum, vol. 1, pp. 142-148, 2010.

[32] Z. Faixová, Š. Faix, Z. Maková, P. Váczi, and M. Prosbová, "Effect of divalent ions on ruminal enzyme activities in sheep," Acta Veterinaria, vol. 56, pp. 17-23, 2006.

[33] E. Tvrdá, Z. Kňažická, L. Bárdos, and N. Lukac, "Dose- and time-dependent effect of copper ions on the viability of bull spermatozoa in different media," Journal of Environmental Science and Health A, vol. 9, pp. 1294-1300, 2012.

[34] A. Kwenang, M. J. Kroos, J. F. Koster, and H. G. Van Eijk, "Iron, ferritin and copper in seminal plasma," Human Reproduction, vol. 2, no. 5, pp. 387-388, 1987.

[35] O. F. Abdul-Rasheed, "Association between seminal plasma copper and magnesium levels with oxidative stress in Iraqi infertile men," Omar Medical Journal, vol. 25, pp. 168-172, 2010.

[36] M. Eghbali, S. M. Alavi-Shoushtari, S. Asri-Rezai, and M. H. K. Ansari, "Calcium, magnesium and total antioxidant capacity (TAC) in seminal plasma of water buffalo (Bubalus Bubalis) bulls and their relationships with semen characteristics," Veterinary Research Forum, vol. 1, pp. 12-20, 2010.

[37] A. K. Chandra, P. Sengupta, H. Goswami, and M. Sarkar, "Effects of dietary magnesium on testicular histology, steroidogenesis, spermatogenesis and oxidative stress markers in adult rats," Indian Journal of Experimental Biology, vol. 51, no. 1, pp. 37-47, 2012.

[38] B. Stegmayr, P. O. Berggren, G. Ronquist, and B. Hellman, "Calcium, magnesium, and zinc contents in organelles of prostatic origin in human seminal plasma," Scandinavian Journal of Urology and Nephrology, vol. 16, no. 3, pp. 199-203, 1982.

[39] D. M. Townsend, K. D. Tew, and H. Tapiero, "The importance of glutathione in human disease," Biomedicine \& Pharmacotherapy, vol. 57, no. 3, pp. 145-155, 2003.

[40] S. E. Chia, C. N. Ong, L. H. Chua, L. M. Ho, and S. K. Tay, "Comparison of zinc concentrations in blood and seminal plasma and the various sperm parameters between fertile and infertile men," Journal of Andrology, vol. 21, no. 1, pp. 53-57, 2000.

[41] H. Fuse, T. Kazama, S. Ohta, and Y. Fujiuchi, "Relationship between zinc concentrations in seminal plasma and various sperm parameters," International Urology and Nephrology, vol. 31, no. 3, pp. 401-408, 1999.

[42] Y. C. Lin, T. C. Chang, Y. J. Tseng et al., "Seminal plasma zinc levels and sperm motion characteristics in infertile samples," Chang Gung medical journal, vol. 23, no. 5, pp. 260-266, 2000.

[43] M. R. Kanwal, N. U. Rehman, N. Ahmad et al., "Bulk cations and trace elements in the Nili-Ravi buffalo and crossbred cow bull semen," International Journal of Agriculture and Biology, vol. 2, pp. 302-305, 2000.

[44] I. M. W. Ebisch, C. M. G. Thomas, W. H. M. Peters, D. D. M. Braat, and R. P. M. Steegers-Theunissen, "The importance of folate, zinc and antioxidants in the pathogenesis and prevention of subfertility," Human Reproduction Update, vol. 13, no. 2, pp. 163-174, 2007.
[45] A. H. Colagar, E. T. Marzony, and M. J. Chaichi, "Zinc levels in seminal plasma are associated with sperm quality in fertile and infertile men," Nutrition Research, vol. 29, no. 2, pp. 82-88, 2009. 

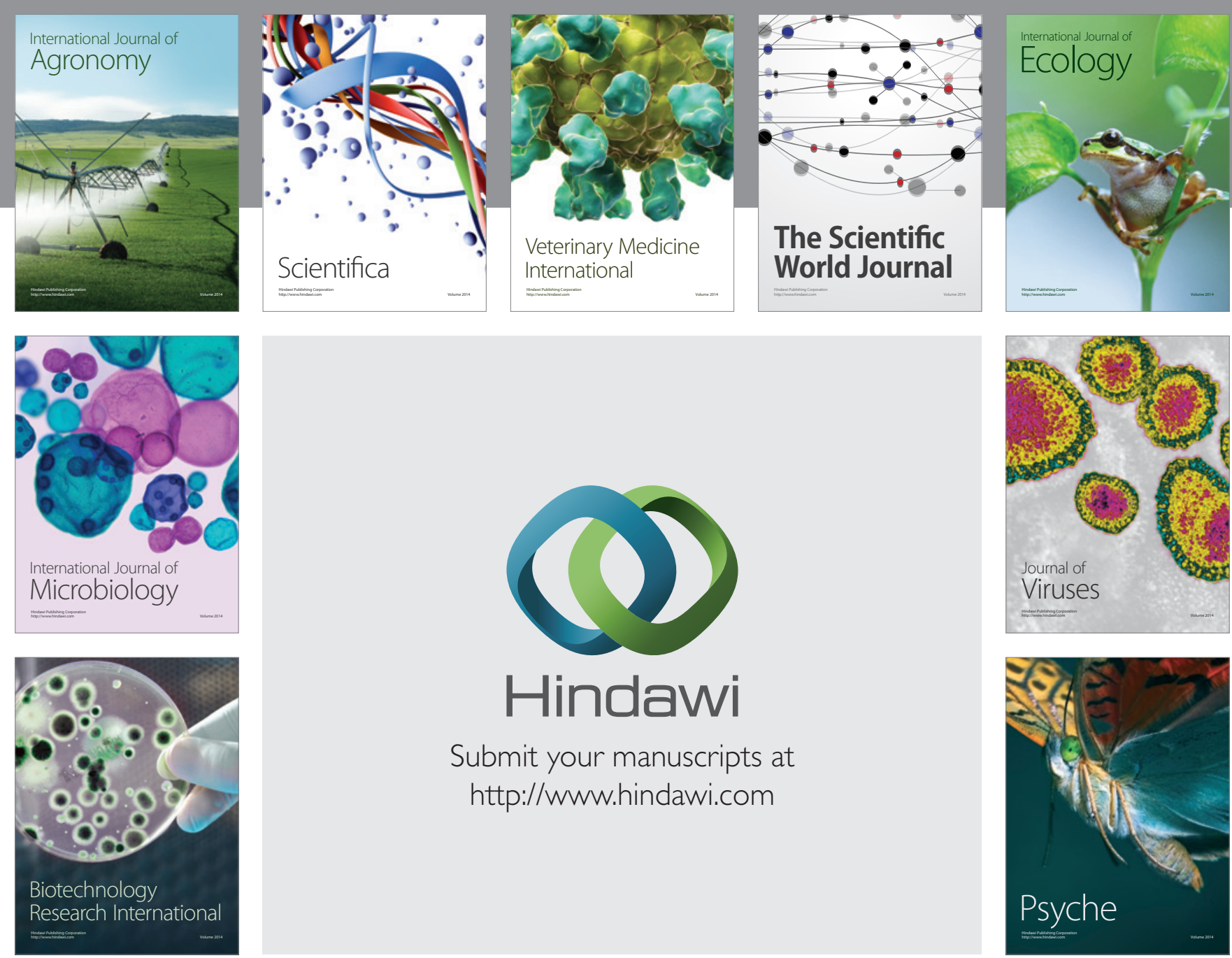

Submit your manuscripts at http://www.hindawi.com
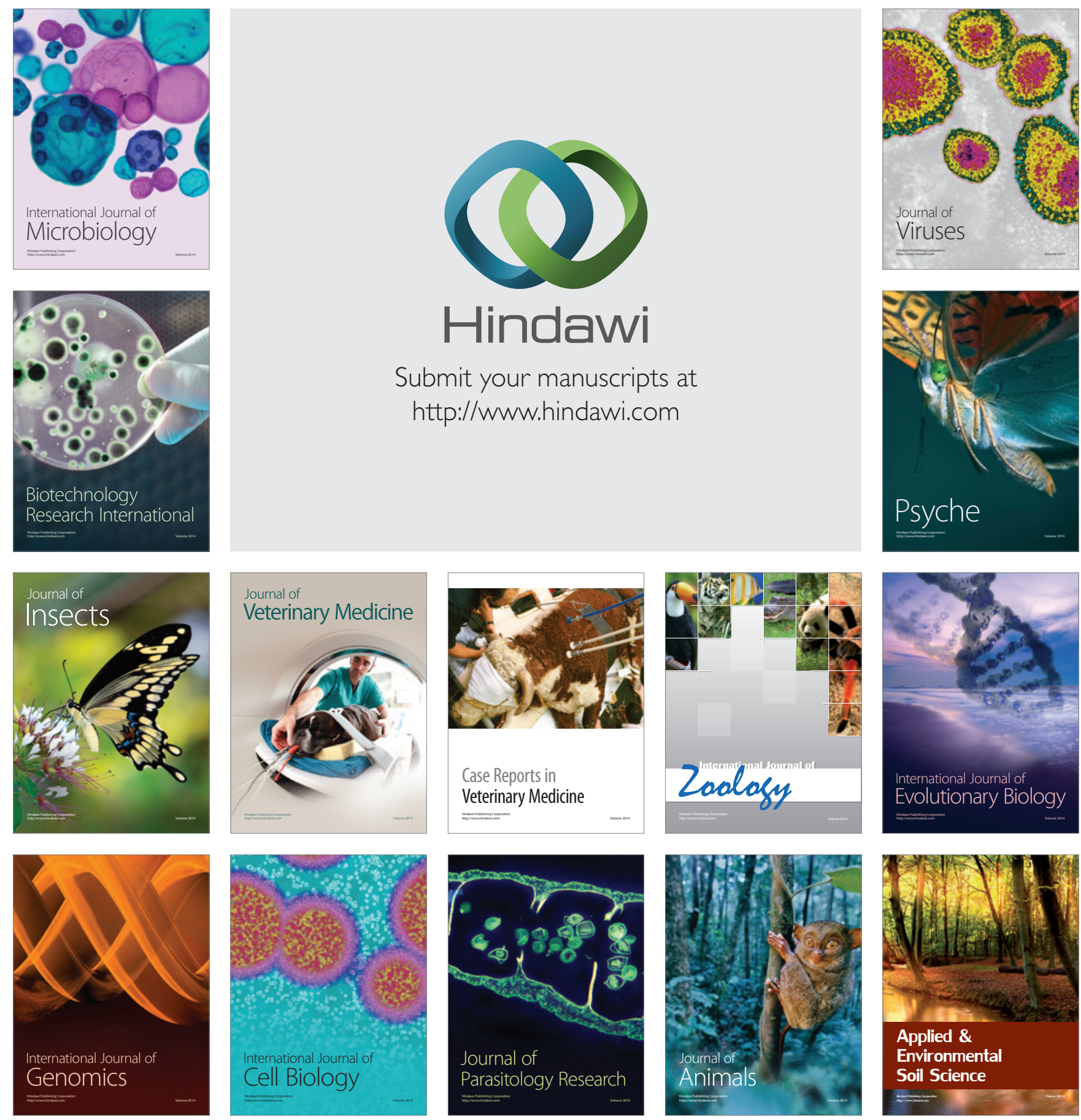